\title{
When Theoretical Knowledge Is Not Enough: Introduction of an Explanatory Model on Nurse's Pain Management
}

\author{
Katrin Blondal ${ }^{1}$ and Sigridur Halldorsdottir ${ }^{2}$ \\ ${ }^{1}$ Landspitali -National University Hospital of Iceland, University of Iceland, \\ School of Health Sciences, Faculty of Nursing, Reykjavik, \\ ${ }^{2}$ School of Health Sciences, University of Akureyri, Akureyri, \\ Iceland
}

\section{Introduction}

Relieving the suffering of patients is a paramount responsibility for all health professionals. The fact that hospitalised patients still suffer from pain despite increasing technology and a wealth of research during recent decades, calls for an audit and new approaches in pain management. Nurses are professionally responsible for pain assessment and the administration of analgesia and are often considered the key persons in the management of pain. However, for many reasons nurses are unable to achieve the desired results of pain relief. Our study on nurses' experiences of caring for patients in pain indicates that previous studies in this field have often been limited to isolated aspects of pain management (Blondal \& Halldorsdottir, 2009). Furthermore, they have been rather negative towards nurses. Our position is that many researchers have not appreciated the complexity of the nurse's multifaceted assignment of caring for patients in pain. We suggest that knowledge, in this respect, may often have been too narrowly defined. We challenge statements that propose that nurses do not believe that pain relief is a priority for nurses (Brockopp et al., 1998) or their responsibility (Twycross, 2002). Successful pain relief may provide satisfaction for the nurses involved (Blondal \& Halldorsdottir, 2009), which is a rarely identified outcome by means of professional achievements. Various research results indicate that nurses' knowledge is less than adequate (Howell et al., 2000; Kuuppelomäki; 2002a; Van Niekerk \& Martin, 2002). Therefore, the main methods that have previously been employed in order to improve nurses' performance and to achieve better pain control are formal education about pain assessment and the use of pain medication. Interestingly, programmes that aim at increasing this knowledge, however, often fail to help in diminishing patients' pain. Some programmes may demonstrate changes in practice (e.g. Carr, 2002) where other findings are contradictory regarding their effectiveness, indicating that the effect of nurses' re-education is not maintained over time (Howell et al., 2000) and that more theoretical knowledge does not necessarily correlate with patients reporting less pain (Watt-Watson et al., 2001). Furthermore, Wilson's (2007) survey on nurses' knowledge of pain also indicates that nurses may be incapable of managing pain, despite their knowledge of the existence of the patients' pain. It is, therefore, important to search for other explanations for inadequate pain management of 
nurses. Therefore, perhaps other patterns of knowledge are needed in addition to the often traditional emphasis on formal education about pain assessment and analgesics.

\subsection{Aim of the theory}

Theory is the acknowledged foundation to practise methodology, professional identity and the growth of formalized knowledge. Practice must not only be evidence based but also theory based. Hence, pain management must be theory based because theories serve as a broad framework for practice and may also articulate the goals of a profession and its core values. Our aim was to develop a theory, an explanatory model, which can explain nurses' complex task of pain management.

\section{Methodology}

In our evaluation of the various methods for this theory development we found theory synthesis as described by Walker and Avant (2004) a good method for constructing our explanatory model. They posit that more theory synthesis is needed to advance practice disciplines so we found a perfect fit. In the theory synthesis the theorists combine isolated pieces of information that may even be theoretically unconnected. Theory synthesis entails constructing a theory from study findings and scholarly writings, which may be numerous. It enables the theorist to organise and integrate a large number of findings into a single theory which can be presented as a model. The theory put forth in this chapter is based on 11 study findings, e.g. on our own phenomenological study on nurses' experience of taking care of patients in pain and ten other research findings from various researchers about: nursing advocacy; moral obligation; organisational barriers; patient based hindrances; and the nurse-doctor relationship (see Table 1). All these different studies helped us to clarify the manifold task of a nurse's pain management. This method can be compared with painting a picture where in step one the picture is drawn and step two (the literature in this case) is used to compare the "picture" drawn with other similar "pictures" for confirmation and clarification. In step three the picture is presented (Figure 1).

\section{Findings}

The theory provides a holistic view of the complicated task of relieving pain. The main tenets of this theory are: the role of the nurses as the patient's advocates, multiple patterns of knowledge and the doctor-nurse relationship. The theory is introduced in the form of an exploratory model which illustrates the main tenets, how they interact and how other aspects simultaneously mould nurses' actions and reactions while taking care of patients in pain (Figure 1).

\subsection{The explanatory model}

To understand and explain the nurses' central role of caring for patients in pain and their potential for providing adequate pain management, their position may be portrayed as that of patients' advocates (Mallik, 1997) within a goal-directed mission aimed at patients' pain relief. In figure 1, this journey is presented in an explanatory model where its main tenets have been arranged into a figure with a definite beginning and an end from top to bottom. As may be seen from the four central tenets of the model, acting as patient's advocate, moral obligation, formal and tacit knowledge, knowing persons and the system, initially dominate, followed by the concepts of internal and external hindrances, as well as potential outcomes. 


\begin{tabular}{|c|c|c|c|}
\hline $\begin{array}{l}\text { Authors, } \\
\text { published }\end{array}$ & Research & Participants, N & Data collection \\
\hline $\begin{array}{l}\text { Blondal \& } \\
\text { Halldorsdottir, } \\
2009\end{array}$ & $\begin{array}{l}\text { The challenge of caring for } \\
\text { patients in pain: from the } \\
\text { nurse's perspective }\end{array}$ & $\begin{array}{l}\text { Nurses caring for } \\
\text { patients with pain in } \\
\text { hospital wards, } N=10\end{array}$ & $\begin{array}{l}20 \text { in-depth } \\
\text { interviews }\end{array}$ \\
\hline $\begin{array}{l}\text { De Schepper et. } \\
\text { al, } 1997\end{array}$ & $\begin{array}{l}\text { Feelings of powerlessness in } \\
\text { relation to pain: ascribed } \\
\text { causes and reported strategies }\end{array}$ & $\begin{array}{l}\text { Community nurses } \\
\text { caring for cancer } \\
\text { patients with pain, } \\
N=24\end{array}$ & $\begin{array}{l}13 \text { individual } \\
\text { and } 3 \text { group } \\
\text { interviews }\end{array}$ \\
\hline Jenks, 1993 & $\begin{array}{l}\text { The pattern of personal } \\
\text { knowing in nurse clinical } \\
\text { decision making }\end{array}$ & $\begin{array}{l}\text { Nurses working in } \\
\text { various hospital } \\
\text { settings, } \\
\mathrm{N}=23\end{array}$ & $\begin{array}{l}\text { Four focus } \\
\text { groups/ } \\
\text { participant } \\
\text { observation }\end{array}$ \\
\hline $\begin{array}{l}\text { Kuuppelomäki, } \\
2002\end{array}$ & $\begin{array}{l}\text { Pain management problems in } \\
\text { patients' terminal phase as } \\
\text { assessed by nurses in Finland }\end{array}$ & $\begin{array}{l}\text { Nurses on inpatient } \\
\text { wards of } 32 \text { municipal } \\
\text { health centres, } \\
N=328\end{array}$ & $\begin{array}{l}\text { Questionnaire } \\
\text { and an open end } \\
\text { question }\end{array}$ \\
\hline Mallik, 1997 & $\begin{array}{l}\text { Advocacy in nursing - } \\
\text { perceptions of practising } \\
\text { nurses }\end{array}$ & $\begin{array}{l}\text { Experienced nurses } \\
\text { from various settings, } \\
N=104\end{array}$ & $\begin{array}{l}\text { Focus group } \\
\text { interviews }\end{array}$ \\
\hline $\begin{array}{l}\text { Malloy et al, } \\
2009\end{array}$ & $\begin{array}{l}\text { Culture and organizational } \\
\text { climate: nurses' insights into } \\
\text { their relationship with } \\
\text { physicians }\end{array}$ & $\begin{array}{l}\text { Nurses from various } \\
\text { settings in } 4 \text { countries, } \\
N=42\end{array}$ & Focus groups \\
\hline Nagy, 1999 & $\begin{array}{l}\text { Strategies used by burns } \\
\text { nurses to cope with the } \\
\text { infliction of pain on patients }\end{array}$ & $\begin{array}{l}\text { Nurses within } \\
\text { paediatric and adult } \\
\text { burn units, } \\
\mathrm{N}=32\end{array}$ & $\begin{array}{l}84 \text { unstructured } \\
\text { interviews }\end{array}$ \\
\hline Nash et al., 1999 & $\begin{array}{l}\text { Pain and the administration of } \\
\text { analgesia: what nurses say }\end{array}$ & $\begin{array}{l}\text { Registered nurses and } \\
\text { BSc nursing students in } \\
\text { acute and community } \\
\text { settings, } \\
\mathrm{N}=19\end{array}$ & $\begin{array}{l}\text { Three focus } \\
\text { group } \\
\text { interviews }\end{array}$ \\
\hline $\begin{array}{l}\text { Oberle \& } \\
\text { Hughes, } 2001\end{array}$ & $\begin{array}{l}\text { Doctors' and nurses' } \\
\text { perceptions of ethical } \\
\text { problems in end-of-life } \\
\text { decisions }\end{array}$ & $\begin{array}{l}7 \text { doctors and } 14 \text { nurses } \\
\text { working in acute care } \\
\text { adult medical-surgical } \\
\text { areas, } N=21\end{array}$ & $\begin{array}{l}\text { Unstructured } \\
\text { interviews }\end{array}$ \\
\hline $\begin{array}{l}\text { O'Connor \& } \\
\text { Kelly, } 2005\end{array}$ & $\begin{array}{l}\text { Bridging the gap: a study } \\
\text { of general nurses' perceptions } \\
\text { of patient advocacy in Ireland }\end{array}$ & $\begin{array}{l}\text { Practicing nurses in } \\
\text { hospitals, } \\
\mathrm{N}=20\end{array}$ & $\begin{array}{l}3 \text { focus group } \\
\text { interviews }\end{array}$ \\
\hline $\begin{array}{l}\text { Van Niekerk \& } \\
\text { Martin, } 2002\end{array}$ & $\begin{array}{l}\text { The impact of the nurse- } \\
\text { physician professional } \\
\text { relationship on nurses' } \\
\text { experience of ethical dilemmas } \\
\text { in effective pain management }\end{array}$ & $\begin{array}{l}\text { Nurses within public } \\
\text { and private settings, } \\
\mathrm{N}=1,015\end{array}$ & Questionnaire \\
\hline
\end{tabular}

Table 1. Key research used to develop the theory 


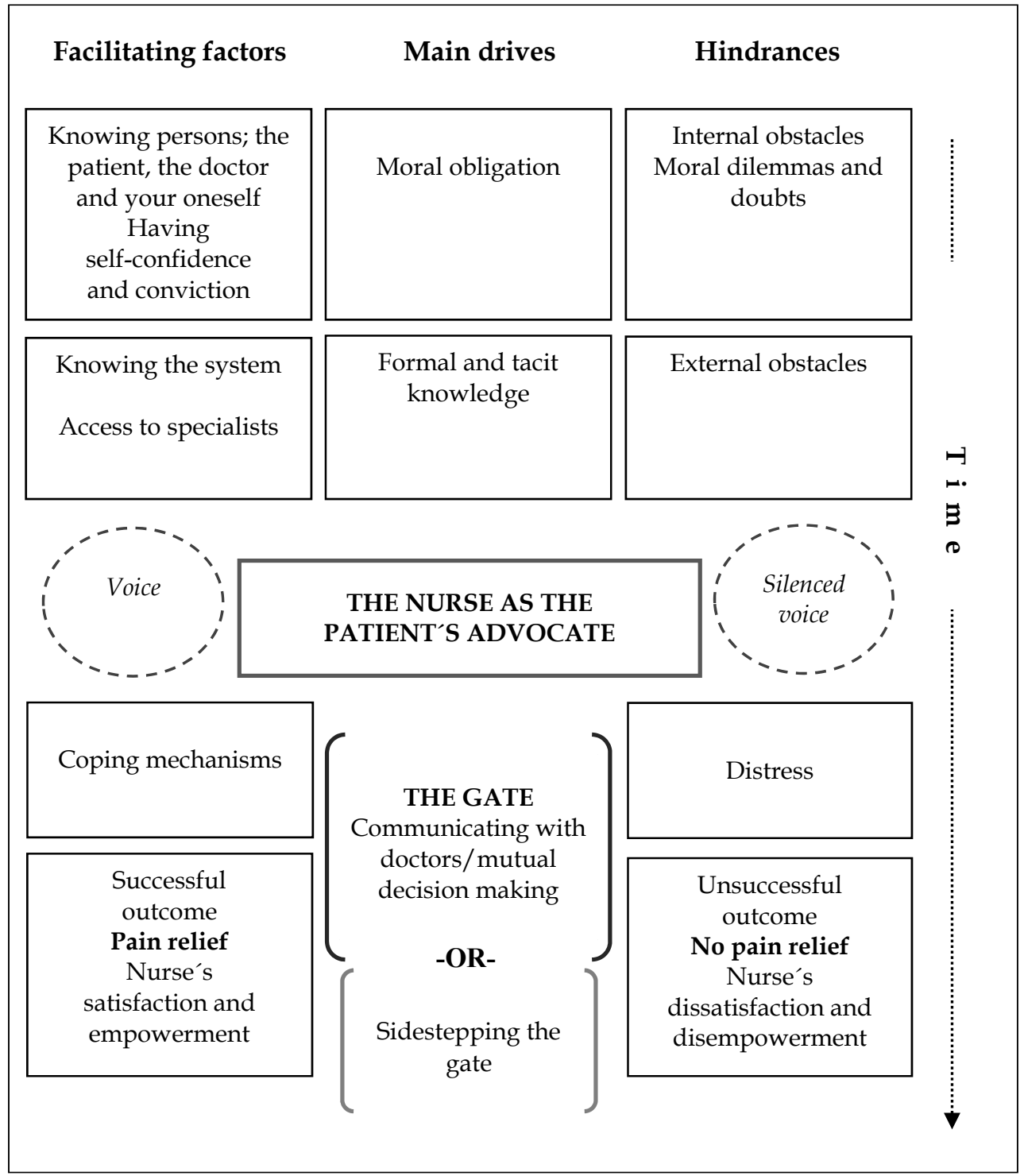

Fig. 1. An explanatory model of nurses' pain management

\subsection{Nurses' two main drives: Moral obligation and formal and tacit knowledge}

The first two concepts we introduce in our explanatory model are moral obligation (Mallik, 1997; Oberle and Hughes, 2001) and formal and tacit knowledge (Blondal \& Halldorsdottir, 2009; Mallik, 1997; Nash et al., 1999). We propose that on the nurses' journey to fulfil their mission of relieving patients' pain these two important drives prevail, as illustrated in figure 2 in the shadowed boxes. 


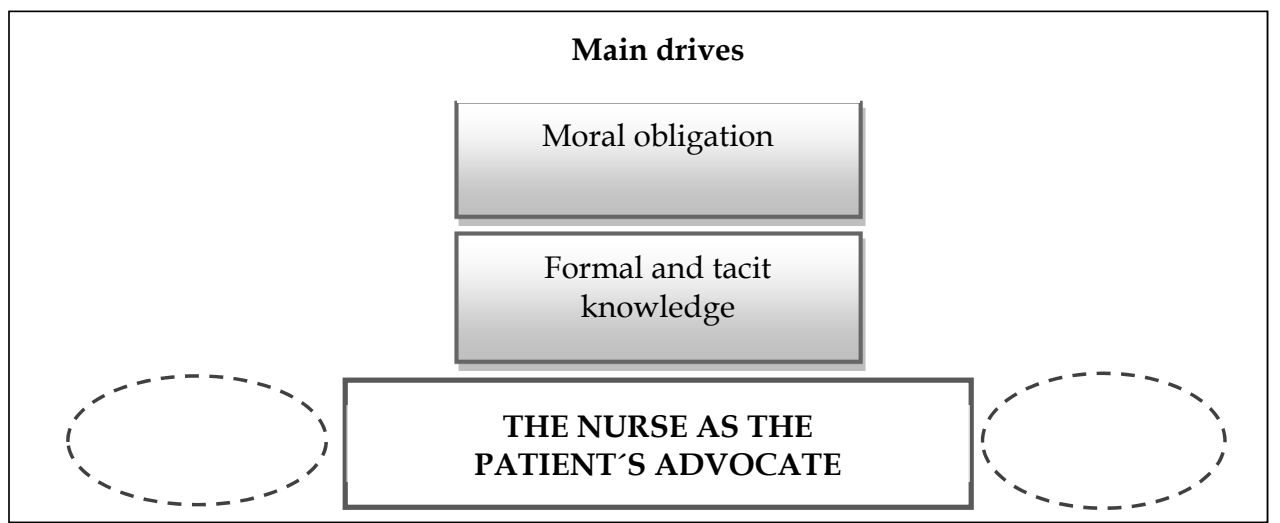

Fig. 2. Nurses' moral obligation and formal and tacit knowledge

The nurses' moral orientation is displayed in accounts like this one: "If the patients report pain, then they're in pain ... and of course you must do something about it" (Blondal \& Halldorsdottir, 2009, p. 4). Possessing formal or theoretical knowledge about pain assessment, pain management and medication is of importance but tacit knowledge is no less important, as experience and learning from other colleagues creates a sense of self confidence and increased empowerment in following their convictions to be the patient's advocate (Blondal \& Halldorsdottir, 2009; Mallik, 1997; Nash et al., 1999). "I suppose I believe advocacy is utilizing our own clinical knowledge as well as our own knowledge of the patient and putting the two of them together and then doing what you feel is best for the patient." (O'Connor \& Kelly, 2005, p. 460). This approach assists nurses to keep on advocating and relating with patients and doctors (Blondal \& Halldorsdottir, 2009).

\subsection{The nurse as the patient's advocate}

As may be seen from our model, its central tenet portrays the position of the nurse as the patient's advocate (Figure 3). Here, the mission's journey begins with the nurse's assessment of the patient's pain, which leads to further decisions and reactions and where the nurse will direct his or her responses; what she or he can solve alone and what problems must be referred to physicians (Blondal \& Halldorsdottir, 2009).

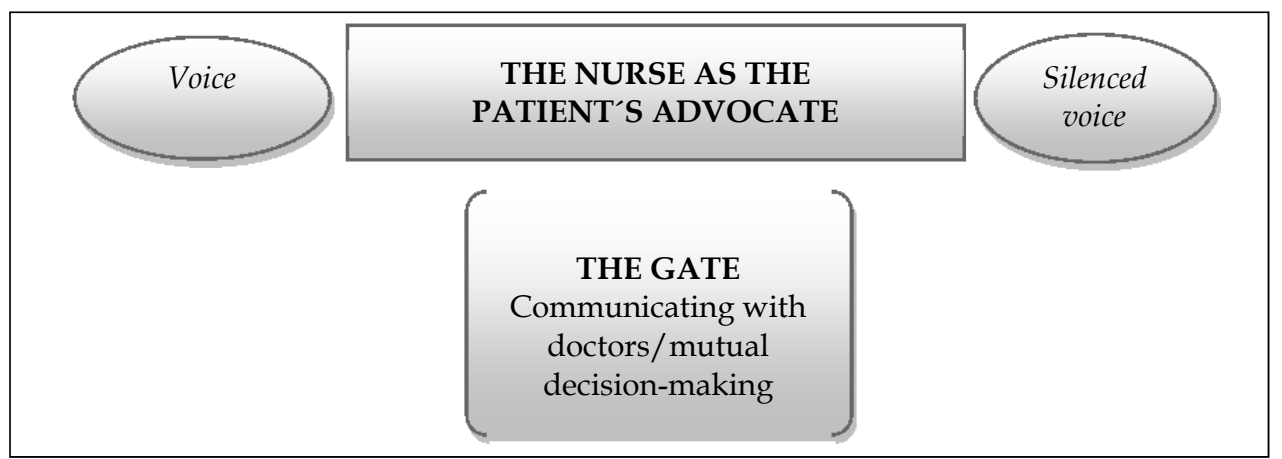

Fig. 3. Central position of the nurse as the patient's advocate 


\subsubsection{Communicating with doctors at the gate/mutual decision-making}

Since medication is often the major pain treatment, and physicians are required to be responsible for all drug prescriptions, a crucial element in this process is the nurses' contribution to mutual decision-making with the doctor, where nurses assume the responsibility of advocates (Blondal \& Halldorsdottir, 2009). At this point, which may be referred to as "the gate", having a voice is pivotal for nurses (Blondal \& Halldorsdottir, 2009; Van Niekerk and Martin, 2002) because they represent the patient, and by using their influence they try to fulfil their mission (Blondal \& Halldorsdottir, 2009; Jenks, 1993; O'Connor \& Kelly, 2005). As two different nurses put it: "Well, unfortunately the decisionmaking is not ours. We are restricted to what's ordered... I mean, if the doctor's ordered it, you can't very well make a decision" (Nash et al., 1999, p. 186), and further: "I don't stand by and watch the patients and do nothing if I think they are wild with pain, I keep on pushing until something is done." (Blondal \& Halldorsdottir, 2009, pp. 5-6). If the nurse and the doctor do not reach reciprocal decision or agreement the nurses may have to keep on insisting or else give up -- feeling silenced (Malloy, 2009; Blondal \& Halldorsdottir, 2009). “We don't have any final authority - perhaps that's what's most difficult...and we have to put up with that, naturally, but it's very important, of course, that we feel we are listened to, that our voice is heard." (Blondal \& Halldorsdottir, 2009, p. 2901). Furthermore, to maintain trust between all involved, the nurses sometimes take on the role of a mediator or intermediary (Blondal \& Halldorsdottir, 2009; O'Connor \& Kelly, 2005), but the importance of co-operation and holding a mutual vision crystallises in this description: "I just think it's lot of give and take between doctors and nursing staff and patients; you've got to work together to actively relieve pain." (Nash et al., 1999, p. 185).

\subsection{Facilitating factors for a successful outcome}

The main drives, moral obligation and formal and tacit knowledge may not be enough for successful pain management. There are several facilitating factors which are necessary to make use of, together with the main drives, in order to achieve a positive outcome of pain management (See Figure 4).

\subsubsection{Knowing the patient}

One of the facilitating factors that are important motivating factors for advocacy (Mallik, 1997), requires that the nurse knows the patient as a person, that is, as an individual, which allows the nurse to interpret information and select individualised interventions (Jenks, 1993). "I think, knowing the patient's background and seeing more than just, say, a medical condition or a surgical wound, that makes you more able to advocate." (O'Connor \& Kelly, 2005, p. 459).

\subsubsection{Knowing the doctor}

In the explanatory model we propose that to know the gatekeeper, i.e. the doctor, greatly influences the nurse's success (Jenks, 1993). "Sometimes I think the nurses are underheard if you go and you're telling the doctor, this patient is in pain. This patient is in pain, ah yeah, we'll change this. The patient is still in pain. Sometimes they don't actually listen to what you're saying. It depends on how you say it, or who you're actually saying it to." (Malloy et al., 2009, p. 726). Then on the other hand, "It's a good feeling when you know that someone respects your opinion and respects your assessment of the patient also." (Jenks, 1993, p. 403). 


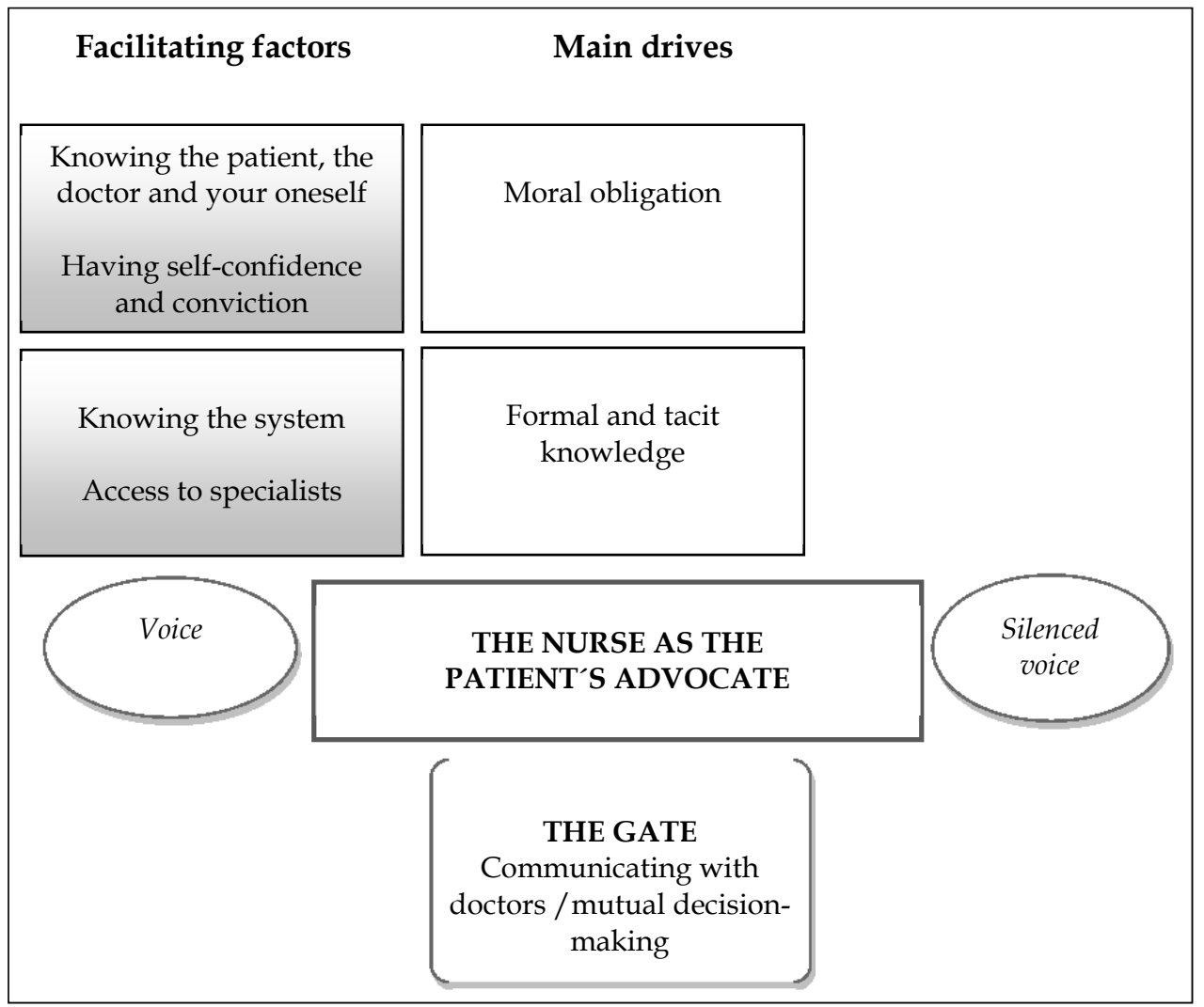

Fig. 4. Facilitating factors; Knowing persons and knowing the system

\subsubsection{Knowing your own self, having self-confidence and conviction}

It is no less important for nurses to know their own potential and believe in themselves, since experience creates a sense of self-confidence and increased empowerment in following their own convictions. Therefore, individual factors influence nurses' decisions on pain management; "I'm quite happy to make those decisions, because I'm happy to be answerable for them...so I do things that I am comfortable with and I feel that I am doing the best for the patient." (Nash et al., 1999, p. 185)

\subsubsection{Knowing the system and access to specialists}

Organizational knowledge, to know how the system works, together with knowledge of the wishes of patients, allows nurses to advocate in an effective way; therefore "[A]n advocate to me would be somebody who uses whatever knowledge they have in a situation to do the best for the patient." (O'Connor \& Kelly, 2005, p. 460). Then having access to a specialist in pain management and pain teams within the organisation is of utmost importance as they serve as nurses' guides and help to turn distress into satisfaction (Blondal \& Halldorsdottir, 2009). 


\subsection{Hindrances to successful pain management}

This journey is complicated, however, by several obstacles that emerge either as internal or external obstacles (see figure 5).

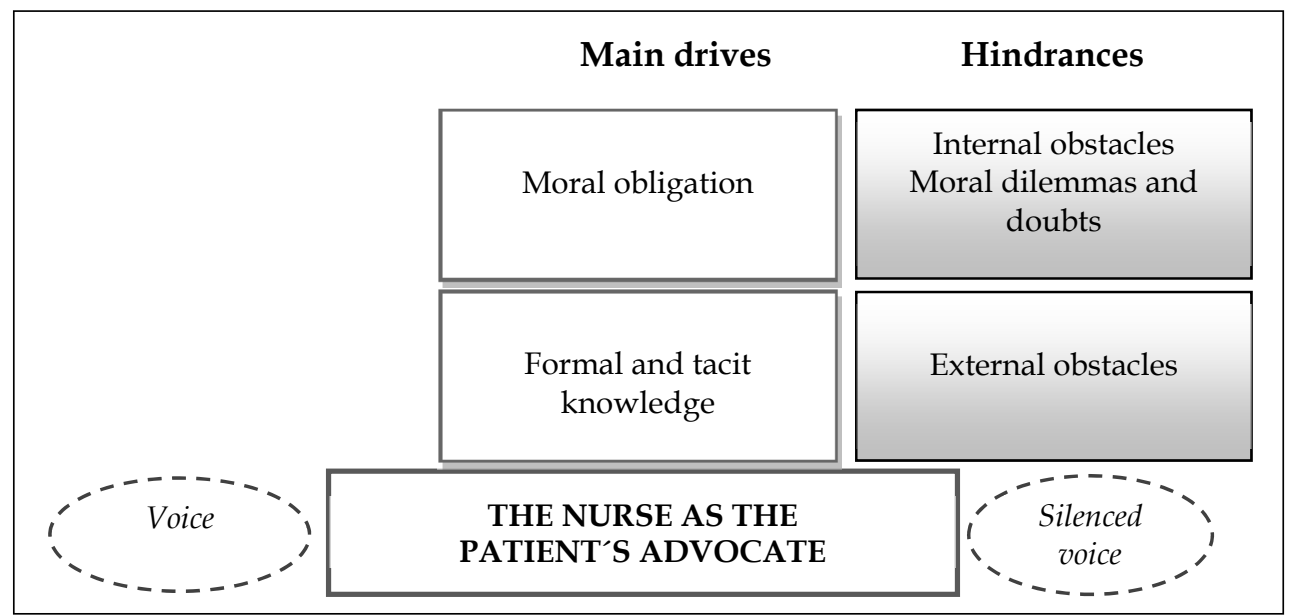

Fig. 5. Internal and external obstacles

\subsubsection{Internal obstacles}

Internal obstacles that can complicate this process are the nurses' inner struggle of moral dilemma and doubt, of doing right and trusting one's own judgement, that appear to be the result of tension between doubt and duty. Here a prevailing feature includes the fear of giving too much medication and caring for addicts (Blondal \& Halldorsdottir, 2009; Nash et al., 1999). "I felt it [to give pain medication to an addict] was a strain, really, on human nature - are you doing something wrong? Or are you doing right? Or are you just cruel to refuse to give it to him? - really, what should you do?"(Blondal \& Halldorsdottir, 2009, p. 5).

\subsubsection{External obstacles}

External obstacles are connected to organisational structures (Kuuppelomäki, 2002a) such as absence of or an inadequate prescription, lack of access to accountable physicians, and the lack of directions and clear rules. Moreover, decisions regarding palliative care are imperative for successful pain relief (Blondal \& Halldorsdottir, 2009; Kuuppelomäki, 2002a); "Accepting death and the transition from acute care to terminal care are a problem." (Kuuppelomäki, 2002a, p. 706). External hindrances may also be patient related, such as their unwillingness to report pain and to accept analgesics (Blondal \& Halldorsdottir, 2009; Kuuppelomäki, 2002a), which further complicates the assessment of pain and pain relief. "He was a difficult man and so withdrawn. You just couldn't get through [to] him and you don't know why not. Cases like that make me feel so uncertain, I start to doubt myself." (De Schepper et al., 1997, p. 424).

\subsection{Coping mechanisms}

Further action can involve the use of various coping mechanisms in order to share the burden, seek better solutions for the patient and/or control their feelings (Blondal \& Halldorsdottir, 2009; Nagy, 1999). (See figure 6.) 


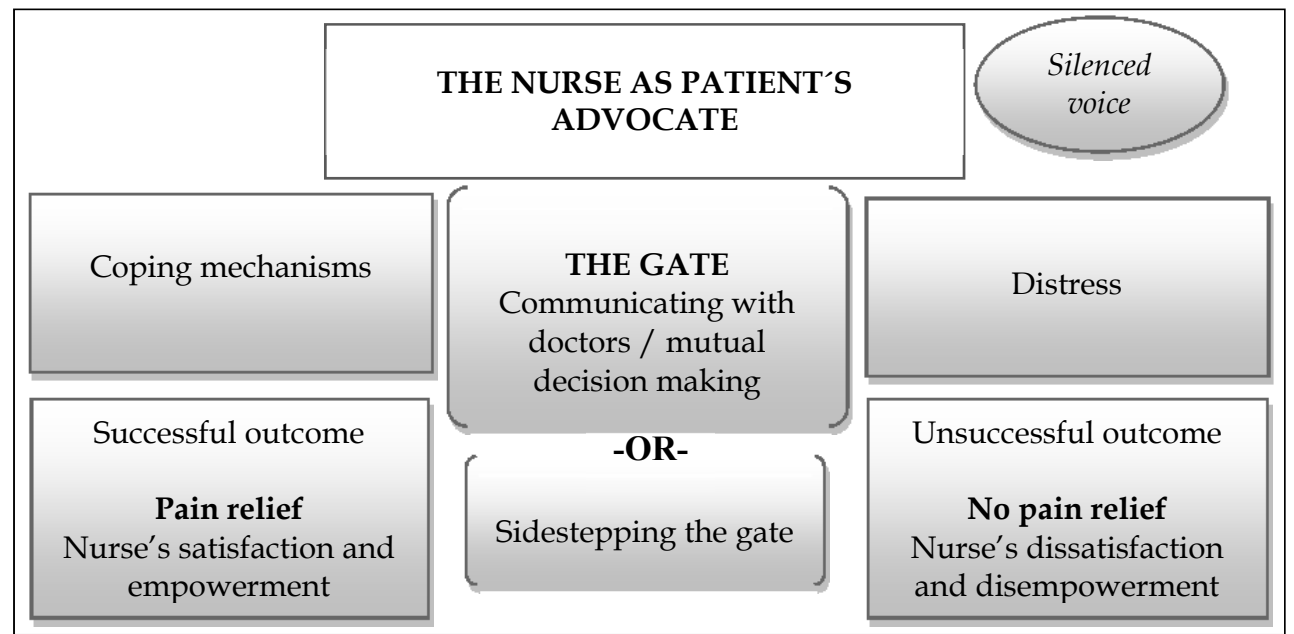

Fig. 6. Coping mechanisms

The most important factor is support provided by colleagues (De Schepper et al., 1997; Nagy, 1999) and specialists in pain management that serve as their guides (Blondal \& Halldorsdottir, 2009). "The people that we work with. You can go up and say 'So-and-so, I can't cope with this any longer! Can you either give me a hand or do it for me?' And people where we are working at the moment will do that. So if we're getting too fed up someone else will either help you out or do it for you so you can go and have a rest. They understand what it's like!" (Nagy, 1999, p. 1433). Furthermore, "I get a lot of support from the team here. They give me [the] feedback I need and I can have a good moan." (De Schepper et al., 1997, p. 426). Assistance can, therefore, like other coping strategies, transform distress into satisfaction (Blondal \& Halldorsdottir, 2009) which may keep them satisfied despite unfavourable outcomes. Some nurses do sidestep the gate by using independent nursing interventions, take control and thread the risky road of bypassing the gate by altering the medication on their own initiative or bend existing rules and directions (Blondal \& Halldorsdottir, 2009). But this also may be the result of the distress mentioned above.

\subsection{Potential outcomes}

As suggested by this model, the nurse's journey has two potential outcomes, based on the degree to which nurses are able to fulfil their commitments (see figure 7).

Successful pain relief leads to nurses' satisfaction and empowerment and patients' satisfaction and possibly mutual trust (Blondal \& Halldorsdottir, 2009). Conversely, pain management is burdensome when the patients' sufferings are not relieved (Nagy, 1999) or the nurses are silenced, with consequent dissatisfaction and distress (De Schepper et al., 1997; Oberle and Hughes, 2001), disempowerment and possibly mutual distrust. "I think, really, it's one of the more difficult things one experiences... I was so upset inside... so angry inside, not being able to help and not really knowing where to turn, because the doctors said just that [dose of medication], and it didn't work at all, so I was somehow defenceless about what to do." (Blondal \& Halldorsdottir, 2009, p. 6). However, importantly, we want to point out that perceived discomfort or dissatisfaction with the outcome can serve as a drive for further action (Blondal \& Halldorsdottir, 2009; Mallik, 1997). 


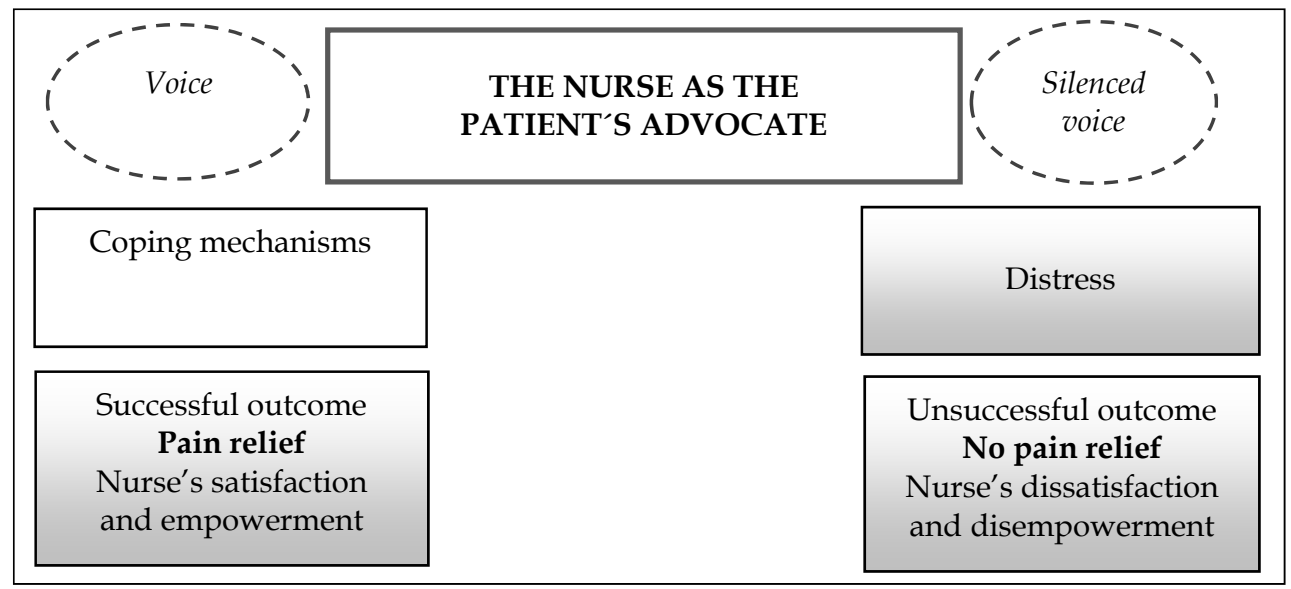

Fig. 7. Potential outcomes

From this overview we conclude that theoretical knowledge is only one aspect of nurses' pain management. They require knowledge from various other sources, ethical, personal, and aesthetic, as well as many skills, e.g. communication and negotiation skills, in order to fulfil their obligations and role. In our view, lack of recognition of these other kinds of knowledge may stem from the fact that many studies focus only on isolated aspects of pain management. All too commonly the studies provide only a somewhat fragmented analysis of isolated factors of pain management. In contrast, the explanatory model presented here provides a more holistic view of the nurses' complex situation when caring for patients in pain and may reveal that neglecting these other facets may have contributed to the permanent inadequacy in pain management of patients that is so widely described.

\section{Discussion}

This explanatory model clarifies how nurses require various coexisting patterns of knowledge, within a favourable organisational environment, to be able to perform in accord with their role as key persons in pain management and how their performance may predict a positive or negative outcome for the patient and the nurse. This model further explains the relationships of nurses with patients and physicians where nurses seek to act as patients' advocates and how having a voice is pivotal for nurses. Furthermore, we depict how internal and external barriers can hinder the performance of nurses and how an unsuccessful outcome that evokes profound distress may concurrently stimulate further actions and turn a negative outcome into a more favourable one. This explanatory model of a nurse's journey therefore denotes nurses' encounters with, and reactions to, the multiple demanding assignments they continually meet on their mission towards pain relief.

\subsection{Nurses' two main drives: Moral obligation and formal and tacit knowledge 4.1.1 Knowledge of ethical origins}

According to our explanatory model the role of ethical knowledge in pain management must be highlighted, as it may be the fundamental component needed for nurses to act as advocates 
and to initiate the process of pain management. Our notion of nurses' obligation to relieve pain is supported by several studies (Oberle and Hughes, 2001; O'Connor \& Kelly, 2005; Rejeh et al., 2009). However, it may have been underestimated up till now because even if nurses possess the relevant theoretical knowledge, they may not necessarily make use of it without the requisite motivation.

We want to emphasize that non-professional and professional moral values that motivate and direct individuals' choices can be inculcated through education or socialisation (Omery, 1989), and nurses recognise that a sense of responsibility in pain management needs to be learned (Rejeh et al., 2009). Taylor et al. (1993) also conclude that nurses' education about pain management must include professional ethical obligations and the suitability of their professional values. Importantly, moral values may also be generated by an organisation's philosophy statement or policy (Omery, 1989) and moral values should, therefore, be part of nursing education as well as organisational statements.

\subsubsection{Formal and tacit knowledge}

In accordance with our propositions, professional responsibility and moral obligation are considered key initiates for advocacy. Twycross (2002) posits that in order to advocate, a theoretical knowledge base is needed. Vaartio et al. (2006) and O'Connor \& Kelly (2005) add to this by stating that theoretical as well as practical knowledge of pain management is a necessary antecedent of advocacy. Where sound empirical knowledge about pain assessment and various methods for management of pain are vital, it must be kept in mind that nurses learn no less through experience, where they learn to utilise their own potential and personal knowledge through their own practice and role modelling. This drive for taking action by using theoretical or formal knowledge along with experience and selfconfidence is congruent with Mallik's (1997) statement that 'intervening conditions' facilitate advocacy. These factors have also been found important for nurses' decisionmaking (Nash et al., 1999). Where knowledge of theoretical origins may be the type of knowledge that is most easily recognised and is emphasised during formal education at school and in continuous education, we stress that the role of tacit knowledge gained through experience and role modelling has more rarely been pointed out, perhaps because it is rather of personal and aesthetic origins. Importantly, as we see it, this knowledge supplements formal knowledge, for instance in the early stages of the process where nurses assess the patient's pain.

\subsection{The nurse as patient's advocate in pain management}

Patients in pain have been recognised as a vulnerable group of patients that are in need of nurses to advocate on their behalf (Ware et al., 2011), and nurses see it as their role to safeguard their interests (Blondal \& Halldorsdottir, 2009; Ware et al., 2011). As portrayed in our explanatory model nurses assume a central role in assessing and managing patients' pain. However, since doctors are responsible for prescribing analgesia, nurses' concerns about pain relief are often affected by their relationship with the doctors (Kuuppelomäki, 2002a; Taylor et al., 1993; Van Niekerk and Martin, 2002).

\subsubsection{Communicating with doctors at "the gate" and mutual decision-making}

On the nurses' journey the gate, where they enter these relations with the gatekeeper-the doctor, is an important turning point (Blondal \& Halldorsdottir, 2009). Having a voice at the 
gate is pivotal, because there the nurses represent the patient, and by using their influence try to fulfil their mission. Subsequently, the doctor decides what medication the patient can or cannot receive; i.e. whether the nurses pass through the gate (Blondal \& Halldorsdottir, 2009). Within the gate the nurses can also assume the role of 'conciliator' or 'intermediary'. Nurses' accounts of their advocating position have, therefore, also been described as 'bridging the gap' between the patients and the medical profession. This involves the translation of information between patients and doctors and in both directions (O'Connor \& Kelly, 2005). As we envision it, yet another aspect of personal knowledge is revealed here where, inevitably, nurses must communicate with doctors to achieve the best outcome for patients.

Many nurses do not find it difficult to communicate with doctors or to confront them and are ready to push boundaries to acquire what the patient needs (Blondal \& Halldorsdottir, 2009; Vaartio et al., 2008; Ware et al., 2011). For others, communicational problems are a matter of fact and they feel uncomfortable about trespassing on the doctors' domain (De Schepper et al. 1997; Willson, 2000). Nurses in cancer-related home care, for instance, complain about physicians' lack of knowledge and collaboration, and problems with contacting them (Ferrell et al., 1993). Nurses then also describe physicians' fear of overmedicating patients with dementia or delirium in medical wards (Coker et al., 2010). Communicational problems cause feelings of powerlessness and distress (Blondal \& Halldorsdottir, 2009; Malloy et al., 2009) and ethical dilemmas and they are sometimes punished for their advocating activities (Clabo, 2008; Mallik, 1997; Malloy et al., 2009). Mallik (1997) maintains that to achieve their goals, advocates often play the doctor-nurse game of recommending actions without appearing to do so (Stein et al., 1990) or assume the attitude of a 'stubborn rebel' with an over-determined and even hostile behaviour (Stein et al., 1990). In our study, however, the nurses emphasise assertiveness, rather than pushiness, for success (Blondal \& Halldorsdottir, 2009). When nurses are straightforward in their requests, this could be explained by their perceptions of being respected and having a voice, and therefore in keeping with Van Niekerk and Martin (2002) that nurses who feel adequately consulted by physicians are more likely to initiate the consultation process. The use of assertiveness further matches the argument of Keenan et al. (1998) that conveying ideas in a forceful and confrontational manner increases the likelihood for successful collaboration. We claim that when nurses choose to bypass the gate by bending rules (Blondal \& Halldorsdottir, 2009; Ware et al., 2011) despite the risk of jeopardising their career, this might indicate a lack of self-confidence, negotiating competence or communicational competence skills. For nurses, ethical problems may often be related to their hierarchical position, where their voices are not heard or they are being silenced in spite of their professional knowledge (Blondal \& Halldorsdottir, 2009; Malloy et al., 2009; Oberle and Hughes, 2001). From this, it might be understood that the views of nurses and doctors are incompatible, for instance because of the different orientation of care versus cure (Malloy et al., 2009). However, doctors can also experience an inability to exercise moral agency and experience powerlessness, because of hierarchical structures, and they are faced with the same kinds of ethical dilemmas as nurses. Furthermore, the obligation to respond is the same for all and this difference could rather be explained by different roles and responsibilities and unawareness of each others' responses (Oberle and Hughes, 2001). This also may reflect the reality that nurses and doctors act independently, without mutually agreed principles or practices rather than as a team in managing pain (Kuuppelomäki, 2002a). Although this statement is made in regard to end-of-life situations, we conclude that 
this could also apply to other pain management decisions and call for more discussions about the ethical aspects of pain management across professions.

\subsection{Facilitating factors for a successful outcome}

As represented in our explanatory model, facilitating factors for successful advocacy and a favourable outcome require knowing persons and the system. Jenks' (1993) exploration of nurses' clinical decision-making, proposing that clinical decisions depend on the quality and dynamics of nurses' interpersonal relationships is in harmony with our interpretation of the process from pain assessment to reaction. However, we also want to add the dimension of knowing your own self and the organisation that also are essential facilitating factors. These important features that enhance nurses' possibilities for using their knowledge and moral motivation are opposed to the factors that hinder them in making use of their potential, and may, to some degree, be used to overcome their negative effects.

\subsubsection{Knowing the patient}

As repeatedly has been pointed out, insufficient pain assessment by nurses interferes with successful pain relief (Carr, 2002). According to McCaffery (Pasero et al., 1999, as cited in McCaffery, 1968) "[P]ain is whatever the experiencing person says it is, existing whenever he says it does" (p. 17). However, because individuals express pain very differently, this definition creates some problems for nurses. For instance, although the risk of addiction is minor (McCaffery et al., 1990), caring for a patient who is, or is suspected of being, an abuser can be very stressful (Blondal \& Halldorsdottir, 2009; Nash et al., 1999). Moreover, McCaffery and Ferrell (1997) assert that nurses must appreciate that "the only scientific tool for measuring pain intensity is the patient's report using a pain rating scale" (p. 183). These scales may, however, be difficult to use with patients that are disoriented (Coker et al., 2010) or unconscious (Kuuppelomäki, 2002a) and many nurses are hesitant to use them (Schafheutle et al., 2001). Then many elderly patients suffer in silence with their pain and discomforts and do not seek help and more effort is required if those with pain are to be identified, supported and cared for as Gudmannsdottir \& Halldorsdottir (2009) suggest. Whereas the use of various pain scales for pain assessment build on theoretical knowledge, conversely, knowing the patient as a person can greatly assist nurses to assess the patient's pain (Blondal and Halldorsdottir, 2009); this approach is more related to personal and aesthetic knowledge. Knowing the patient as a person strongly facilitates the assessment of patients' needs and clinical decision-making (Liaschenko, 1997), and allows nurses to interpret information and select individualised interventions (Takman and Severinsson, 1999). Furthermore, the nurse-patient relationship is a motivating factor for advocacy (Mallik, 1997; O'Connor \& Kelly, 2005) and analysing the patient and the situation is a fundamental element of advocacy (Vaartio et al., 2008). Therefore, we suggest that more emphasis is given to this special aspect of pain management. Still, yet another pattern of knowledge may also be needed here; unknowing the patient. When nurses admit to themselves that they do not know the patient and his or her point of view, it allows them to hold their former biases and prejudices in abeyance (Munhall, 1993). We suggest that assuming this type of knowledge is of utmost importance as it may prevent nurses from making assumptions about patients' pain intensity that is based on diagnosis and course of treatment (Clabo, 2008; Manias, 2003; Schafheutle et al., 2001) that is associated with underestimation of pain (Sjöström et al., 2000), and a barrier to effective pain relief (Schafheutle et al., 2001). Adopting this stance of unknowing could also avoid the 
stereotyping of patients, such as those who may be addicts, homeless or prisoners (Rejeh et al., 2009) or with a lifestyle that may affect nurses' pain management behaviours (Wilson, 2007). Therefore, we advise that strategies nurses use to connect to patients which may be based on personal knowledge (Carper, 1978) and unknowing (Munhall, 1993) are highlighted along with the current emphasis on using pain rating scales (e.g. Paice and Cohen, 1997).

According to our model, competent communication with patients may be a powerful way to overcome internal hindrances in addition to theoretical knowledge about pain assessment, addiction, respiratory depression and other possible side effects of pain medication that also may stem from the ethical orientation of preventing harm to the patients. When nurses' emphasise individualised pain management, knowing the patient as a person, recognising his/her special needs and responding to these needs on the basis of envisioned results, portrays the importance of aesthetic knowledge and comprehension of the particularity of the situation (Carper, 1978). Empathy is also an important component mode of the aesthetic pattern in nursing (Carper, 1978), and apparent in nurses' accounts of pain management (Blondal \& Halldorsdottir, 2009; Rejeh et al., 2009) and should be not only acknowledged but utilised more often.

\subsubsection{Knowing the doctor}

Since nurses call for equality, mutual decision-making and respect for their judgement (Blondal \& Halldorsdottir, 2009), knowing the doctor is a factor worth further exploration. In accordance with our explanatory model Jenks (1993) maintains that knowing the doctor creates mutual trust in each others' perceptions. Therefore, a good nurse-physician relationship, in accordance with our metaphor of nurses passing through the gate, knowing the gatekeeper may add to optimal pain relief and consequently affects nurses' and patients' wellbeing. It is, therefore, imperative that both doctors and nurses be aware of the need for good rapport and be knowledgeable about good communication techniques and that both groups of professionals make every effort to encourage collaboration and to find ways to get to know each other as persons. Again, we propose that personal knowledge and communicational skills that nurses must use in relations with patients and doctors is vital because, as before, possessing theoretical knowledge and the motivation to use it (moral orientation) may become of little use if not employed because of lack of communication or negotiating abilities or lack of self-confidence or if nurses cannot react because their voice is silenced. Therefore, nurses must be taught to act as the patients' advocates, represent themselves and act like the patients' representative.

\subsubsection{Knowing oneself, having self-confidence and conviction}

We further want to draw attention to how nurses' awareness of their feelings such as distress and empathy, recognition of their own capabilities, self-confidence and persistence may be important facilitating factors. As mentioned before, motivational factors such as experience and self-confidence are congruent with Mallik's (1997) 'intervening conditions' that facilitate advocacy and are important for nurses' decision-making (Nash et al., 1999). As further discussed later, emotional responses such as anger and frustration are also potent motivators for advocacy (Mallik, 1997). Such knowledge is of both personal and aesthetical origins and nurses must learn to identify and accept such feelings and be empowered to use them to be capable of following their convictions, both for their own sakes and for the good of the patient. According to our model, nurses that hold such knowledge and believe in 
themselves are more capable of entering into and coping positively with difficult relations with others - patients, families and doctors, and are more likely to gain what is needed for a positive outcome both for the patients and themselves.

\subsubsection{Knowing the system}

Yet another facet that is worth more consideration is nurses' knowledge of the organisation. Knowing the system and the environment is part of nurses' advocacy, for instance when nurses must mediate between the patient and the system through interpretation of medical terminology or advocating for a group of patients (O'Connor et al., 2005). It also seems necessary to recognise what options or resources are available within the organisation, for instance whom to turn to for assistance. Here, the support of professionals - specialists in pain management within organisations, must be present at all times to assist them in dealing with difficult cases (Blondal and Halldorsdottir, 2009; Nash et al., 1999). Moreover, nurses must recognise the availability of specialists and when they should be contacted and involved.

\subsection{Hindrances for successful pain management}

As the model portrays, some inhibiting factors hinder nurses' potentials for taking action and therefore interfere with their drives, moral obligation, and formal and tacit knowledge. It may also be seen that these factors are somewhat in opposition to the facilitating factors. The main obstacles are grouped as external - originating in the nurses' environment, or internal - concerned with inner doubts or dilemmas. This gives an example of how these model elements are interconnected and should not be taken out of the immediate context.

\subsubsection{Internal hindrances}

As previously mentioned, nurses' moral motivation is complicated by some dilemmas as the nurses encounter variable decisional and ethical conflicts (Taylor et al. 1993) that directly affect the pain management process and its outcome. The dilemma of inflicting pain to serve other goals of treatment (De Schepper, 1997; Willson, 2000), fear of giving too much pain medication because of respiratory depression (Ferrell et al., 1991; Howell et al., 2000; Wilson, 2007), sedation (Howell et al., 2000), fear of the addictive properties of narcotics (Brockopp et al., 1998), and doubt whether the pain is real (Nash, 1999; Rejeh et al., 2009) has repeatedly been described. So are the difficulties of distinguishing between physical pain and psychological distress (Kuuppellomäki, 2002a), patients' non-compliance in accepting analgesia (Kuuppellomäki, 2002a), patients' reticence (De Schepper et al 1997; Rejeh et al., 2009) and nurses' concerns about giving a dying person the last dose (Brockopp et al., 1998), as for some, hastening death through pain relief is morally unacceptable (O'Rourke, 1992). Ethical problems may also arise from a lack of permission to be honest with patients (Rejeh et al., 2009) or because of the attitudes of family members towards pain medication (Kuuppelomäki, 2002a). Nurses also frequently describe how difficult it is for them to care for patients that are known abusers or suspected of being addicts, and believing their words (Blondal \& Halldorsdottir, 2009; Nash et al., 1999; Rejeh et al., 2009). Dilemmas may also be caused by preconceived notions about certain groups of patients that negatively interfere with nurses' decision-making (Brockopp et al., 2003). Interestingly, Van Niekerk and Martin (2002) point out that nurses with greater knowledge of pain assessment are less likely to experience ethical conflicts regarding overmedication, addiction or doubt about the existence of pain. Hence, more knowledge could prevent such ethical conflicts. Accounts 
like this further sustain our claims about how the separate parts introduced in our model are interconnected and cannot be separated from the complete picture.

\subsubsection{External obstacles}

Organisational barriers have formerly been extensively described, where lack of time, workload (Ware et al., 2011; Rejeh et al., 2009) financial restraints and staffing cutbacks (Oberle and Hughes, 2001; Rejeh et al., 2009), restraints of routine (Willson, 2000), insufficient prescribing of analgesics (Schafheutle et al., 2001; Kuuppelomäki, 2002a) based on habits instead of individualised needs (Boer et al, 1997), and unavailability of physicians (Kuuppelomäki, 2002a; Rejeh et al., 2009) interfere with pain relief. Other related hindrances that are part of the system have also been identified such as unavailable non-pharmacological pain relief measures and disorganised systems of care (Coker et al., 2010). Rejeh et al. (2009) also point out that defective equipment and interruptions can lead to ethical problems in pain management. The importance of a decision on palliative care for good pain relief is endorsed by Kuuppelomäki (2002b) who reports physicians' hesitancy about starting terminal care, and delayed decisions of using a strong analgesia (Kuuppelomäki, 2002a). The organisation must, therefore, provide an optimal organisational environment since organisational barriers such as unclear rules, lack of prescriptions or time and resources such as specialised pain services, may hinder nurses from acting according to their best knowledge, potential and goals. The presence of prescriptions, rules and directives are important to be able to give the patient what she or he needs. Inflexible protocols and strict policies or routines, on the other hand, impede good pain management (Rajeh et al., 2009; Willson, 2000) resulting in the nurses giving up and leaving them feeling silenced and disempowered (Blondal \& Halldorsdottir, 2009; Malloy et al., 2009). Alternatively, nurses may feel compelled to choose to bypass the gate, by bending rules (Blondal \& Halldorsdottir, 2009; Ware et al., 2011), to obtain favourable results for the patient, as is portrayed in our model. Our emphasis on organisational structures is supported by the results of Willson's (2000) participant observation study on factors affecting analgesia administration; Willson suggests that because of the interplay between multiple organisational and interpersonal features, more education of the nurses will not necessarily improve the administration of analgesics.

\subsection{Coping mechanisms}

How nurses cope with their challenges predicts to some extent how they perceive the outcome of pain relief and they seem to use various methods to cope and protect themselves. Applying methods such as concentrating on patients' positive attributes is a component of strategies that prevent burnout (Simoni and Paterson, 1997), and sharing feelings with colleagues (De Schepper et al., 1997; Nagy, 1999) and having the opportunity to stand back from situations (De Schepper et al., 1997; Rejeh et al., 2009) are consistent with strategies that reduce powerlessness (De Schepper et al., 1997). Seeking and receiving support from pain teams and specialists in pain management is vital, and such assistance can transform distress into satisfaction. Ironically, those who accept the responsibility as seeing to pain relief run the risk of experiencing ethical problems which may lead to a sense of loss of control and subsequently burnout, resulting in decreased quality of care (Schmitz et al., 2000). If nurses give up their advocating efforts and instead assume coping methods such as avoidance, which indicates unsuccessful coping (Simoni and Paterson, 1997), it may desensitise them to patients' needs (Nagy's, 1999), which means in turn that they may not be 
willing or able to attend to patients' suffering. Such strategies should, therefore, be detected, and those nurses helped to adopt more constructive coping strategies.

\subsection{Potential outcomes of pain management and advocacy}

Effective pain relief may provide satisfaction, both by means of professional achievements and benefits for the patient and the nurse (Blondal \& Halldorsdottir, 2009; De Schepper et al. 1997; Vaartio et al., 2008). However, such positive outcomes are seldom mentioned. We believe that this aspect should receive more attention and nurses should be enabled to reap satisfaction from overcoming challenges and learning from them. As successful pain relief may enhance autonomy and a sense of empowerment, this is relevant to both quality of pain management and job satisfaction. Conversely, much more attention is given to the negative aspects: dissatisfaction, distress and frustration (e.g. Nagy, 1998; Söderhamn and Idvall, 2003) following insufficient or unsuccessful pain management that leads in turn to nurses' suffering and disempowerment (Blondal \& Halldorsdottir, 2009; Oberle and Hughes, 2001).

\subsubsection{Dissatisfaction and distress as motivators for a successful outcome}

Since dissatisfaction and nurses' distress may be the inevitable results of nurses' inability to ease the patients' pain, for instance because of silencing or lack of resources, it is important to note that nurses' distress can impel further actions. This is in agreement with Mallik's (1997) argument that emotional responses of anger and frustration can be potent motivators for advocacy. It, therefore, seems important that nurses accept and recognise such feelings, not least because those who acknowledge and try to deal with feelings of powerlessness are more capable of coping (De Schepper et al., 1997). All these responses require, once again, both personal and aesthetic knowledge where nurses as individuals must learn to know themselves and their reactions and be able to develop and maintain a view of what they want to achieve with their actions. Here we come back to earlier discussion about nurses' requirements of knowing their own "selves", their own feelings and capabilities.

\section{Further development of this theory}

Theory provides a more complete picture of practice than factual knowledge alone, and theories formulate, identify, and articulate the science and practice of every discipline (Butcher, 2006). Nursing scholars need to identify and articulate the processes and components of the art and science of pain management. This theory is an attempt to do so in an endeavour to continue the discipline's development by assisting in the understanding and practice of creating further theoretical discourse, processes and products for pain management, similar to what Kagan (2006) has described. All theories are reconstructed in the light of new data. The theory presented here is, therefore, seen as always being in the process of emerging, as is our world view. According to Walker and Avant (2004), the next steps in the phases of our theory development are: theory testing involving concept revision, statement revision, and theory revision, followed by further theory testing. We encourage our colleagues to critique the theory and use it to generate research questions and take part in testing the theory as well as in concept, statement and theory revision.

\section{Implications for practice and future research}

From our explanatory model many suggestions can be made about how to contribute to changes in the education of nurses, their work environment and future research. 


\subsection{Nurses' knowledge and formal education}

Firstly, we propose that alterations should be made within nurses' basic education at school and continuous education at the institutional level. Nurses' formal education at school must include extensive knowledge about pain assessment and pain management and it is also necessary that courses are offered regularly within all health care settings on pain assessment, analgesia, adverse reactions, and respiratory depression. However, in addition to the traditional emphasis on the use of pain scales for the assessment of patients' pain, it is also important to emphasise personal and aesthetic knowledge that contains strategies that contribute to knowing and involving the patient, and nurses' availability. Then education about the pain management of dying patients, addiction and prejudices must also be increased, both at schools and within organisations. The ethical aspects of pain management should be included in all courses along with empirical knowledge and should contain discussions about moral responsibility, bioethical principles, nurses' professional code of conduct and the Patients' Rights Act together with religious discussions about pain management. Furthermore, despite differences in educational programmes and the cultures of nurses and doctors, these professions must reach a mutual understanding to achieve suitable and consistent care for their patients (Malloy et al., 2009). One method to bring together their views could, therefore, be to organise courses that these professionals attend together. That said, as nurses' socialisation occurs to a great extent during their nursing education (Stein et al., 1990), nursing students should be taught to make claims for mutual decision-making, to recognise their own potential, and be empowered to make claims for resources and improvements. As many nurses may lack the vocabulary for ethical decision-making, thus contributing to the silenced voices of nurses (Malloy et al., 2009), advocating competence should be taught at school. Moreover, they should be prepared for the need for negotiation, assertiveness, and effective communication. It is necessary that nurses are encouraged to reflect on their experience both as nurse students and as practicing nurses and also to establish positive working relationship with doctors. Moreover, since nurses seem to learn strategies such as self-confidence through role modelling we emphasize that during their nursing education and as novice nurses they should have access to role models for guidance that relate to their use of personal and aesthetic knowledge. During courses about pain management nurses' coping methods should be addressed, and they should be taught to recognise destructive methods and adopt more constructive ones. The method of structured reflection (Johns, 1995), for instance, could be used to assist nurses in learning about their own abilities and responses. However, not only should negative aspects of their practice or difficult cases be inspected, but also the positive ones.

\subsection{Organisational environment}

Firstly, it is imperative that pain relief is highlighted within all health care settings and organisational nursing policies or visions for nursing, which must reflect this important aspect of care. It should be stressed that pain management is a priority and recognised that time and adequate resources are important aspects of pain management. Protocols that exemplify the responsibility of each member of the health care team should exist, but all rules that are created should also be flexible; for instance nurses must be enabled to choose an analgesic from a range of individualised prescriptions. It also seems vital that clear directives exist for the pain relief of addicts and access to support from specialists in the management of this group of patients available at all times. Support from specialists in 
pain management and psychological support at all times are also fundamental. Moreover, the opportunity to discuss difficult cases with philosophers or leaders from different faiths and denominations should be provided in every health care setting. Subsequently, conversations about nurses' ethical responsibilities and dilemmas should be offered and should be open for both nurses and doctors. As pain assessment is partly dependent on positive nurse-patient relationships and knowing the patient as a person, nursing models and interventions that encourage such relations should be introduced and supported. Another aspect of organisational culture that may enhance successful pain management is good collaboration and maintenance of trust between nurses and in the nurse-physician relationships. All efforts that strengthen dialogue and a culture that enables nurses to seek support and advice from colleagues and encourages open discussions about feelings and coping may therefore have positive outcomes in this respect. Lastly, an atmosphere of persistence and seeking the best available solution should be supported.

\subsection{Future research}

The explanatory model can be a great source of ideas for future research. Firstly, a quantitative study could be conducted, to assess nurses' level of empirical, aesthetic and ethical knowledge along with personal knowledge regarding pain relief; including communication, collaboration and coping. Secondly, it would be interesting to explore the ethical component of the nursing and medical curricula and further to investigate to what extent nurses and doctors are guided by moral values in their pain relief at work. Thirdly, studies on how nurses' moral orientation is balanced with the effectiveness of the pain relief they provide could also be conducted. Fourthly, it seems necessary to conduct more studies where the communication of nurses and doctors connected with pain management is explored, for instance by using an ethnographic approach. Fifthly, it seems important to run more field studies within each organization to identify the main obstructions for effective pain management. It seems vital to begin with identifying what hindrances are most prominent before embarking on a campaign for better pain management within organisations. A part of these studies could be to inspect the effects of workload, lack of time and constraining directives on nurses' potentials for providing optimal pain relief.

\section{Conclusion}

Our explanatory model is at odds with statements proposing that pain relief is not the nurses' priority (Brockopp et al., 1998) or their responsibility (Twycross, 2002). We assert, however, that various reasons inhibit the nurses' potential for taking action. We conclude that nurses are the patients' advocates in pain management and successful pain management is rewarded with a sense of satisfaction, empowerment and fulfilment of their duty. They are in a key position to assess and manage pain and their mediatory position within the hospital is unique. It is vital that nurses are adequately prepared for their role educationally by possessing multidimensional knowledge about pain management. We assert that good theoretical knowledge may be inadequate if the nurse does not have the right motivation, i.e. the moral inclination to use it in practice. Furthermore, personal knowledge that nurses must use in relations with patients and doctors is also necessary because theoretical knowledge alone may be of little use if it cannot be employed because of lack of communication or negotiation competence or 
because their voice is silenced. They also need personal knowledge for self-knowledge, and to reflect on their own strengths and weaknesses in order to make better use of their own abilities. Therefore, nurses must be taught to act as the patient's advocate and the patients' representative. This also requires nurses to use their aesthetic knowledge to appreciate the needs of every individual patient. Furthermore, nurses must acknowledge how little they know about some patients who could beforehand be labelled as "difficult". These patterns of knowledge in pain management are interrelated and should therefore be assessed as a whole if pain management is to be enhanced within an organisation or pain management skills in nurses' primary or continuing education. The organisation in turn must provide an optimal environment; a clear statement about pain management and clear but flexible rules on pain management, and provide ample time and resources such as specialised pain services, that otherwise may hinder nurses from acting according to their best knowledge, potentials, and nursing goals. Teamwork and good collaboration between health care professionals must also be supported. The structure and prevailing culture of organisations must therefore be scrutinised before organising improvements in pain management.

All the factors previously mentioned coexist and are interdependent and cannot be taken out of the immediate context, as may be seen from our model. Therefore, developments in pain management that focus only on one aspect of pain management may be ineffective, as many factors affect this process. We, therefore, propose that knowledge in this respect has often been too narrowly defined and we call for a more holistic approach in pain management by nurses and other health care personnel where multiple types of knowledge and skills as well as the organisational context are included and taken into consideration during educational efforts and reform of pain management within organisations.

\section{References}

Blondal, K. \& Halldorsdottir, S. (2009). The challenge of caring for patients in pain: From the nurse's perspective. Journal of Clinical Nursing, Vol.18, No.20, pp. 2897-2906, ISSN 0962-1067

Boer, C., Treebus, A.N., Zuurmond, W.W.A. \& de Lange, J.J. (1997). Compliance in administration of prescribed analgesics. Anaesthesia, Vol.52, No.11, pp. 1177- 1181, ISSN 1365-2044

Brockopp, D.Y., Ryan, P. \& Warden, S. (2003). Nurses' willingness to manage the pain of specific groups of patients. British Journal of Nursing, Vol.12, No.7, pp. 409-415, ISSN 0966-0461

Brockopp, G., Warden, S., Wilson, J., Carpenter, J.S. \& Vandeveer, B. (1998). Barriers to change: A pain management project. International Journal of Nursing Studies, Vol.35, No.4, pp. 226-232, ISSN 0020-7489

Butcher, H.K. (2006). Review of Walker and Avant's newest theory development text. Nursing Science Quarterly, Vol.19, No.2, pp.174-177, ISSN 0894-3184

Carper, B.A. (1978). Fundamental patterns of knowing in nursing. Advances in Nursing Science, Vol. 1, No. 1, pp. 13-23, ISSN 0161-9268 
Carr, E.C.J. (2002). Refusing analgesics: Using continuous improvement to improve pain management on a surgical ward. Journal of Clinical Nursing, Vol.11, No.6, pp. 743752, ISSN 0962-1067

Clabo, L.M.L. (2008). An ethnography of pain assessment and the role of social context on two postoperative units. Journal of Advanced Nursing, Vol.61, No.5, pp. 531-539, ISSN 0309-2402

Coker, E., Papaioannou, A, Kaasalainen, S., Dolovich, L., Turpie, I. \& Taniguchi, A. (2010). Nurses' perceived barriers to optimal pain management in older adults on acute medical units. Applied Nursing Research, Vol.23, No.3, pp. 139-146, ISSN 0897-1897

De Schepper, A.M.E., Francke, A.L. \& Abu-Saad, H.H. (1997). Feelings of powerlessness in relation to pain: ascribed causes and reported strategies: A qualitative study among Dutch community nurses caring for cancer patients with pain. Cancer Nursing, Vol.20, No.6, pp. 422-429, ISSN 0162-220X

Ferrell, B.R., Eberts, M.T., McCaffery, M. \& Grant, M. (1991). Clinical decisionmaking and pain. Cancer Nursing, Vol.14, No.6, pp. 289-297, ISSN 0162-220X

Ferrell, B.R., Taylor, E.J., Grant, M., Fowler, M. \& Corbisiero, R.M. (1993). Pain management at home: Struggle, comfort, and mission. Cancer Nursing, Vol.16, No.3, pp. 169-178, ISSN 0162-220X

Gudmannsdottir, G.D. \& Halldorsdottir, S. (2009). Primacy of existential pain and suffering in residents in chronic pain in nursing homes: A phenomenological study. Scandinavian Journal of Caring Sciences, Vol.20, No.3, pp. 317-327, ISSN 0283-9318

Howell, D., Butler, L., Vincent, L., Watt-Watson, J. \& Stearns, N. (2000). Influencing nurses' knowledge, attitudes, and practice in cancer pain management. Cancer Nursing, Vol.23, No.1, pp. 55-63, ISSN 0162-220X

Jenks, J.M. (1993). The pattern of personal knowing in nurse clinical decision making. Journal of Nursing Education, Vol.32, No.9, pp. 399-405, ISSN 1938-2421

Johns, C. (1995). Framing learning through reflection within Carper's fundamental ways of knowing in nursing. Journal of Advanced Nursing, Vol.22, No.2, pp. 226-234, ISSN 0309-2402

Kagan, P. (2006). Review of Walker and Avant's newest theory development text. Nursing Science Quarterly, Vol.19, No.2, pp. 177-179, ISSN 0894-3184

Keenan, G.M., Cooke, R. \& Hillis, S.L. (1998). Norms and nurse management of conflicts: Keys to understanding nurse-physician collaboration. Research in Nursing and Health, Vol.21, No.1, pp. 59-72, ISSN 1098-240X

Kramer, M. \& Schmalenberg, C. (1993). Learning from success: autonomy and empowerment. Nursing Management, Vol.24, No.5, pp. 58-64, ISSN 0744-6314

Kuuppelomäki, M. (2002a). Pain management problems in patients' terminal phase as assessed by nurses in Finland. Journal of Advanced Nursing, Vol.40, No.6, pp. 701709, ISSN 0309-2402

Kuuppelomäki, M. (2002b). The decision-making process when starting terminal care as assessed by nursing staff. Nursing Ethics, Vol.9, No.1, pp. 20-35, ISSN 09697330 
Liaschenko, J. (1997). Knowing the patient? In Thorne S.E. \& Hayes, V.E. (Eds.), Nursing Praxis: Knowledge and Action, pp. 23-38, Sage, ISBN 0761900101, London

Mallik, M. (1997). Advocacy in nursing - perceptions of practising nurses. Journal of Clinical Nursing, Vol.6, No.4, pp. 303-313, ISSN 0962-1067

Malloy, D.C., Hadjistavropoulos, T., McCarthy, E.F., Evans, R.J., Zakus, D.H., Park, I., Lee, Y. \& Williams, J. (2009). Culture and organizational climate: Nurses' insights into their relationship with physicians. Nursing Ethics, Vol.16, No.6, pp. 719-33, ISSN 0969-7330

Manias, E. (2003). Pain and anxiety management in the postoperative gastro-surgical setting. Journal of Advanced Nursing, Vol.41, No.6, pp. 585-594, ISSN 0309-2402

McCaffery, M. \& Ferrell, B.R. (1997). Nurses' knowledge of pain assessment and management: How much progress have we made? Journal of Pain and Symptom Management, Vol.14, No.3, pp. 175-188, ISSN 0885-3924

McCaffery, M. \& Pasero, C. (1999). Assessment: Underlying complexities, misconceptions, and practical tools. In McCaffery, M. \& Pasero, C. (Eds.), Pain: clinical manual (2nd ed.), pp. 35-102, Mosby, ISBN 081515609X, St. Louis

McCaffery, M., Ferrell, B., O’Neil-Page, E., Lester, M. \& Ferrell, B. (1990). Nurses' knowledge of opioid analgesic drugs and psychological dependence. Cancer Nursing, Vol.13, No.1, pp. 21-27, ISSN 0162-220X

Munhall, P.L. (1993) 'Unknowing': toward another pattern of knowing in nursing. Nursing Outlook, Vol.41, No.3, pp. 125-128, ISSN 0029-6554

Nagy, S. (1999). Strategies used by burns nurses to cope with the infliction of pain on patients. Journal of Advanced Nursing, Vol.29, No.6, pp. 1427-1433, ISSN 0309-2402

Nash, R., Yates, P., Edwards, H., Fentiman, B., Dewar, A., McDowell, J. \& Clark, R. (1999). Pain and the administration of analgesia: What nurses say. Journal of Clinical Nursing, Vol.8, No.2, pp. 180-189, ISSN 0962-1067

O'Rourke, K. (1992). Pain relief: The perspective of catholic tradition. Journal of Pain and Symptom Management, Vol.7, No.8, pp. 485-491, ISSN 0885-3924

Oberle, K. \& Hughes, D. (2001) Doctors' and nurses' perceptions of ethical problems in endof-life decisions. Journal of Advanced Nursing, Vol.33, No.6, pp. 707-715, ISSN 03092402

O'Connor, T. \& Kelly, B. (2005). Bridging the gap: A study of general nurses' perceptions of patient advocacy in Ireland. Nursing Ethics, Vol.12, No.5, pp. 453-67, ISSN 09697330

Omery, A. (1989). Values, moral reasoning, and ethics. Nursing Clinics of North America, Vol.24, No.2, pp. 499-508, ISSN 0029-6465

Paice, J.A. \& Cohen, F. L. (1997) Validity of a verbally administered numeric rating scale to measure cancer pain intensity. Cancer Nursing, Vol.20, No.2, pp. 88-93, ISSN 0162$220 \mathrm{X}$

Pasero, C., Paice, J.A. \& McCaffery, M. (1999). Basic mechanisms underlying the causes and effects of pain. In McCaffery, M. \& Pasero, C. (Eds.), Pain: Clinical manual (2nd ed.), pp. 15-34, Mosby, ISBN 081515609X, St. Louis

Rejeh, N., Ahmadi, F., Mohamadi, E., Anoosheh, M. \& Kazemnejad, A. (2009). Ethical challenges in pain management post-surgery. Nursing Ethics, Vol.16, No.2, pp. 16172, ISSN 0969-7330 
Schafheutle, E.I., Cantrill, J.A. \& Noyce, P.R. (2001). Why is pain management suboptimal on surgical wards? Journal of Advanced Nursing, Vol.33, No.6, pp. 728-737, ISSN 03092402

Schmitz, N., Neumann, W. \& Oppermann, R. (2000). Stress, burnout and loss of control in German nurses. International Journal of Nursing Studies, Vol.37, No.2, pp. 95-99, ISSN 0020-7489

Simoni, P.S. \& Paterson, J.J. (1997). Hardiness, coping, and burnout in the nursing workplace. Journal of Professional Nursing, Vol.13, No.3, pp. 178-185, ISSN 87557223

Sjöström, B., Dahlgren, L.O. \& Haljamäe, H. (2000). Strategies used in post-operative pain assessment and their clinical accuracy. Journal of Clinical Nursing, Vol.9, No.1, pp. 111-118, ISSN 0962-1067

Söderhamn, O. \& Idvall, E. (2003). Nurses' influence on quality of care in postoperative pain management: A phenomenological study. International Journal of Nursing Practice, No.9, Vol.1, pp. 26-32, ISSN 1322-7114

Stein, L.I., Watts, D.T. \& Howell, T. (1990). The doctor-nurse game revisited. New England Journal of Medicine, Vol.322, No.8, pp. 546-549, ISSN 0028-4793

Takman, C. \& Severinsson, E.I. (1999). A description of health care professionals' experiences of encounters with patients in clinical settings. Journal of Advanced Nursing, Vol.30, No.6, pp. 1368-1374, ISSN 0309-2402

Taylor, E.J., Ferrell, B.R., Grant, M. \& Cheyney, L. (1993). Managing cancer pain at home: The decisions and ethical conflicts of patients, family caregivers, and homecare nurses. Oncology Nursing Forum, Vol.20, No.6, pp. 919-927, ISSN 0190-535X

Twycross, A. (2002). Educating nurses about pain management: The way forward. Journal of Clinical Nursing, Vol.11, No.6, pp. 705-14, ISSN 0962-1067

Vaartio, H., Leino-Kilpi, H., Salanterä, S. \& Suominen, T. (2006). Nursing advocacy: How is it defined by patients and nurses, what does it involve and how is it experienced? Scandnavian Journal of Caring Sciences, Vol.20, No.3, pp. 282-92, ISSN 0283-9318

Van Niekerk, L.M. \& Martin, F. (2002). The impact of the nurse-physician professional relationship on nurses' experience of ethical dilemmas in effective pain management. Journal of Professional Nursing, Vol.18, No.5, pp. 276-288, ISSN 87557223

Walker, L.O. \& Avant, K.C. (2004). Strategies for theory construction in nursing (4th ed.). Prentice Hall, ISBN 0838586880, Englewood Cliffs, NJ

Ware, L.J., Bruckenthal, P., Davis, G.C. \& O'Conner-Von, S.K. (2011). Factors that influence patient advocacy by pain management nurses: Results of the American society for pain management nursing survey. Pain Management Nursing, (Epub 2010 Jul 24), Vol.12, No.1, 25-32., ISSN 1524-9042

Watt-Watson, J., Stevens, B., Garfinkel, P., Streiner, D. \& Gallop, R, (2001). Relationship between nurses' pain knowledge and pain management outcomes for their postoperative cardiac patients. Journal of Advanced Nursing, Vol.36, No.4, pp. 535545, ISSN 0309-2402 
Willson, H. (2000). Factors affecting the administration of analgesia to patients following repair of a fractured hip. Journal of Advanced Nursing, Vol.31, No.5, pp. 1145-1154, ISSN 0309-2402

Wilson, B. (2007). Nurses' knowledge of pain. Journal of Clinical Nursing, Vol.16, No.6, pp. 1012-1020, ISSN 0962-1067

Wilson, B. (2009). Can patient lifestyle influence the management of pain? Journal of Clinical Nursing, Vol.18, No.3, pp. 399-408, ISSN 0962-1067 


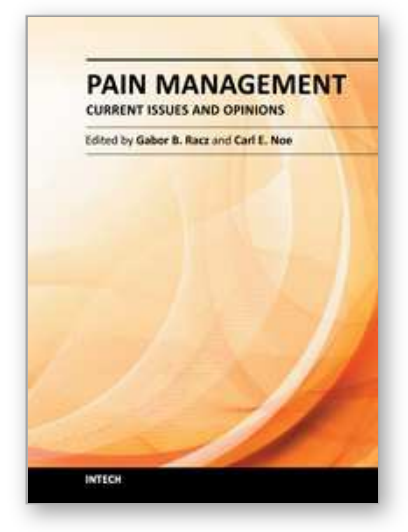

\author{
Pain Management - Current Issues and Opinions \\ Edited by Dr. Gabor Racz
}

ISBN 978-953-307-813-7

Hard cover, 554 pages

Publisher InTech

Published online 18, January, 2012

Published in print edition January, 2012

Pain Management - Current Issues and Opinions is written by international experts who cover a number of topics about current pain management problems, and gives the reader a glimpse into the future of pain treatment. Several chapters report original research, while others summarize clinical information with specific treatment options. The international mix of authors reflects the "casting of a broad net" to recruit authors on the cutting edge of their area of interest. Pain Management - Current Issues and Opinions is a must read for the up-to-date pain clinician.

\title{
How to reference
}

In order to correctly reference this scholarly work, feel free to copy and paste the following:

Katrin Blondal and Sigridur Halldorsdottir (2012). When Theoretical Knowledge Is Not Enough: Introduction of an Explanatory Model on Nurse's Pain Management, Pain Management - Current Issues and Opinions, Dr. Gabor Racz (Ed.), ISBN: 978-953-307-813-7, InTech, Available from: http://www.intechopen.com/books/painmanagement-current-issues-and-opinions/when-theoretical-knowledge-is-not-enough-introduction-of-anexplanatory-model-on-nurse-s-pain-manage

\section{INTECH}

open science | open minds

\section{InTech Europe}

University Campus STeP Ri Slavka Krautzeka 83/A 51000 Rijeka, Croatia Phone: +385 (51) 770447

Fax: +385 (51) 686166 www.intechopen.com

\section{InTech China}

Unit 405, Office Block, Hotel Equatorial Shanghai No.65, Yan An Road (West), Shanghai, 200040, China 中国上海市延安西路65号上海国际贵都大饭店办公楼405单元 Phone: +86-21-62489820

Fax: +86-21-62489821 
(C) 2012 The Author(s). Licensee IntechOpen. This is an open access article distributed under the terms of the Creative Commons Attribution 3.0 License, which permits unrestricted use, distribution, and reproduction in any medium, provided the original work is properly cited. 